\title{
ACCEPTANCE OF SELF-EVALUATION OF TEACHERS IN LOWER PRIMARY SCHOOLS
}

\section{Esad Kurejšepi ${ }^{1}$}

University of Prizren, Faculty of Education

Received: 19.07 .2013$.

Accepted: 30.08 .2013$.
Original scientific paper

UDC:371.136:373.3

\begin{abstract}
Acceptance of self-evaluation as a complex, challenging activities and competencies of teachers ceased to be the issue of his personal choice, so this process the teacher must accept as an unavoidable factor in their professional development and, in the classroom, to take responsibility for the affirmation of pedagogy and design appropriate learning environment for it.
\end{abstract}

Key words: Knowledge, teacher, analysis, teaching, evaluation, self-evaluation

\section{ACCEPTANCE OF SELF-EVALUATION OF TEACHERS IN LOWER PRIMARY SCHOOLS}

Knowledge society requires teachers to take on some new roles including the central place has the ability to self study and evaluation of their work. In addition, the "educational aspect" evaluation means that "good evaluation itself is synonymous with good education of future employees. Experience of participation in the evaluation clearly contributes to all who take part in it, new knowledge and new perspectives on certain issues "(Easton, 1997 \& Možina, 2003).

Because the self-evaluation raises an important factor for professional development and competence of teachers, research task relates to: Examining the at- titudes of teachers in primary and secondary schools on the acceptance of self-evaluation of the process of teaching expressed through the following modes: (1) I do not need to do that, (2) I do not intend to do it, (3) radio / la would if it were a legal obligation, (4) do it occasionally, and (5) do it often. Hypothesis test devised in conjunction with this task as follows: Teachers in primary and secondary schools to accept self-evaluation.

Figure 1 the review of the results obtained with regard to immediate professional specialty of primary school teachers.

${ }^{1}$ Correspondence to:

Esad Kurejšepi, Faculty of Education, University of Prizren

Rečane, Prizren 20530. Kosovo

Phone: +377 44389144

E-mail: recane_esad@hotmail.com 


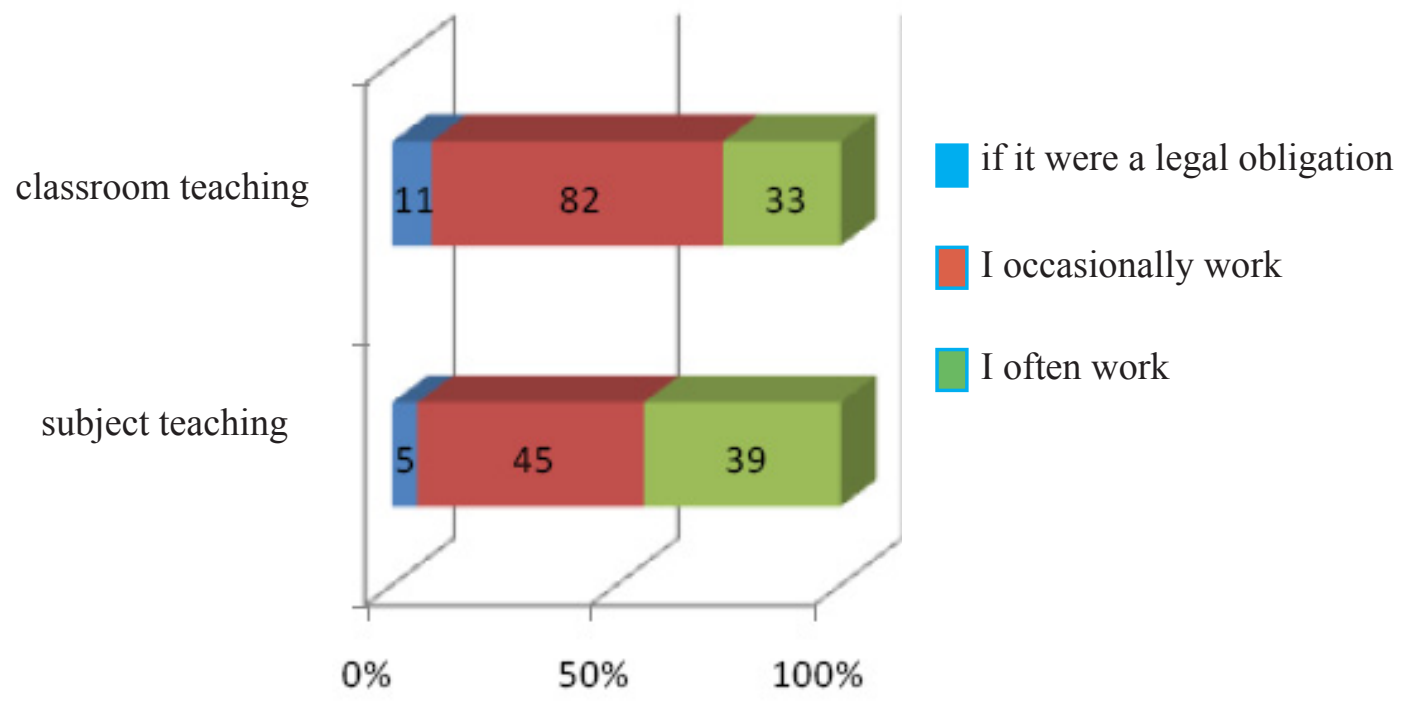

Figure 1. Acceptance of self-evaluation with regard to immediate professional specialty of primary school teachers

Results show that $59.1 \%$ of respondents said they occasionally carry out the process of self-evaluation work, $33.5 \%$ of the self-evaluation of work often, and the $7.4 \%$ that was done only in cases where it was required by law. There was no statistically significant difference in the acceptance of self-evaluation between the class teachers and teaching $($ Chi square $=1.367, \mathrm{p}>0.05)$.

Figure 2 the review of the results obtained with regard to immediate professional specialty high school teachers.

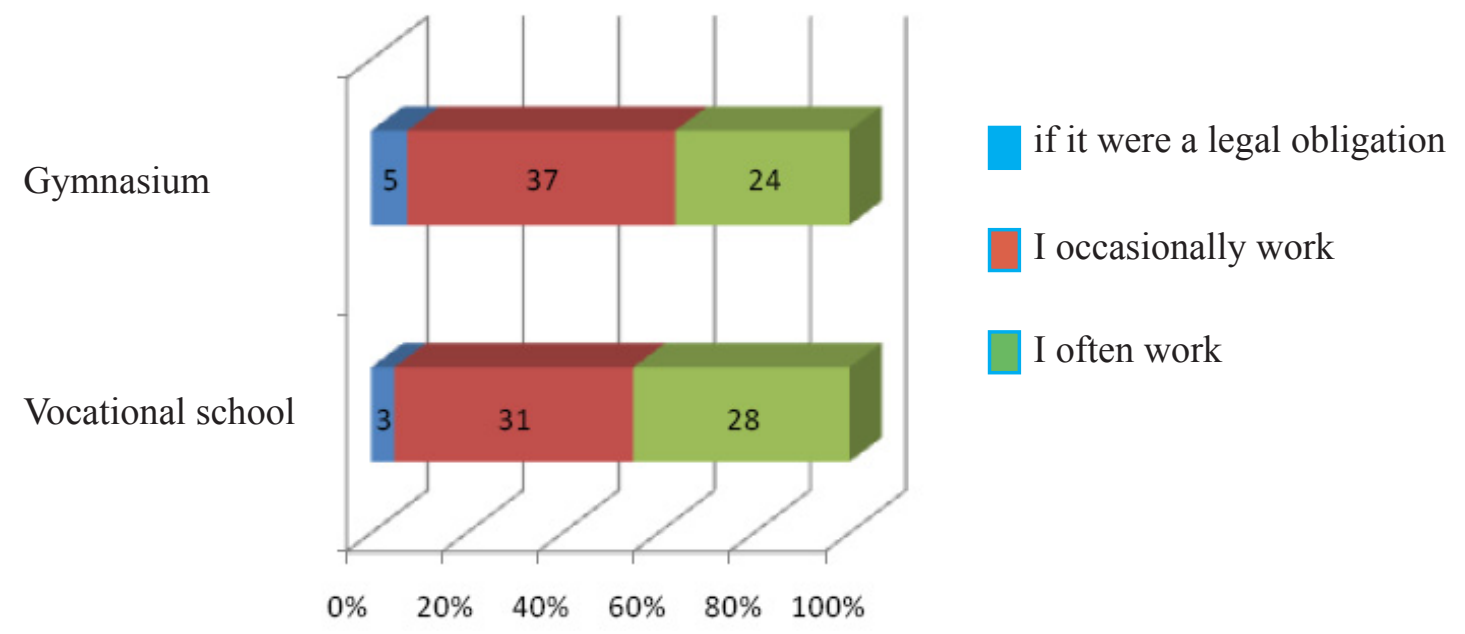

Figure 2 Acceptance of self-evaluation with regard to immediate professional specialty high school teachers

Results show that $53.1 \%$ of respondents said they occasionally carry out the process of self-evaluation work, $40.6 \%$ of the self-evaluation of work often, and the $6.3 \%$ that was done only in cases where it was required by law. There was no statistically significant difference in the acceptance of self-evaluation of teacher professional high school and high school teachers $($ Chi square $=1.935, \mathrm{p}>0.05)$. 
Although the results obtained by statistical analysis of the data suggests that the majority of teachers reported that occasionally or frequently conduct self-evaluation, the structure of the issues preventing a clearer interpretation of the results. The interpretation of "occasionally" and "often carried out self-evaluation" in some subjects may mean that conducted annually, and it is often referred to as self-evaluation of spending, while other subjects the same frequency can be treated as self-evaluation periodically conduct selfevaluation. In future works, examining acceptance and frequency of self-evaluation procedures should be clearly structured answers, eg as follows: once a month, once a year or so.

Figure 3 the results of the acceptance of self-evaluation with respect to half of teachers in primary and secondary schools.

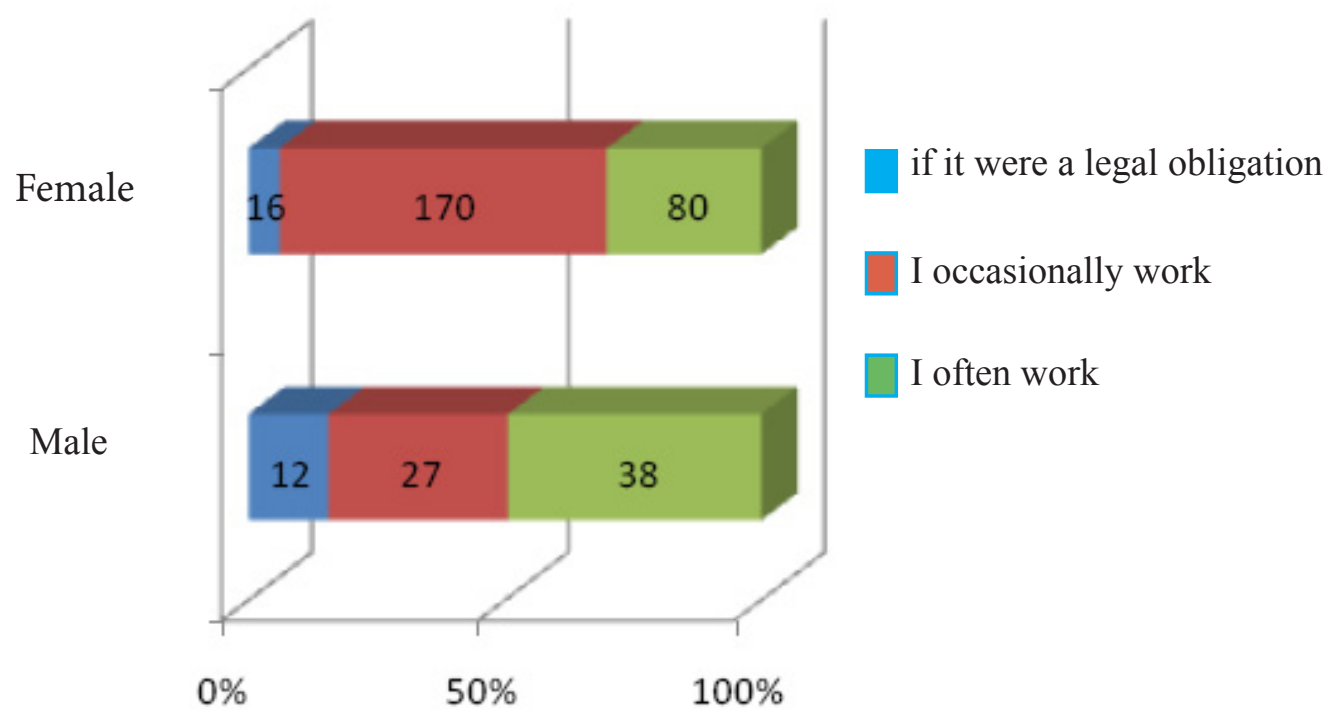

Figure 3 Acceptance of self-evaluation with respect to half of teachers in primary and secondary schools

Given half the respondents are significantly different in acceptance self-evaluation (Chi square $=12.392, \mathrm{p}$ $<.05$ ). Male respondents more likely to say they often practice self-evaluation, while female respondents more likely to say that occasionally practiced selfevaluation. Because it is possible that male and female respondents differ in their assessment of the frequency of self-evaluation (ie it is intermittent, which is a common self-evaluation), we can not claim that this information really means that teachers frequently or sufficiently implemented self-evaluation.

Based on the data obtained from the previous analysis, we can conclude that teachers in primary and secondary schools do not accept sufficiently self-evaluation of the teaching process, nor in this respect exploited the opportunities offered by the evaluation theory.

\section{CONCLUSION}

The results obtained by statistical analysis of data in the first task showed that the first working hypothesis of this research has not been confirmed. Although approximately $63 \%$ of the teachers stated that occasion- ally conducts self-evaluation, these results do not yet indicate that the implementation of continuous selfevaluation, and the results do not support the idea that conducts a systematic process of self-evaluation of teaching. Therefore, we cannot claim to be teachers of primary and secondary schools to accept selfevaluation as a continuous process in the school. This raises new questions, which can be the basis for future research in order to overcome the current state accountability of teachers and schools for their own development. Lack of acceptance of self-evaluation is perhaps complexity and difficulty.

\section{REFERENCES}

Easton, P. A. (1997). Sharpening our tools: Improving Evaluation in Adult and Nonformal Education. Hamburg: Unesco institute for Education: German Foundation for international Development.

Kundačina, M. (2003). Funkcija evaluativnih istraživanja u reformi obrazovanja. Godišnjak za psihologiju [Annual of Psychology] 2. pp. 45-56.

Kundačina, M. and Brkić, M. (2004). Pedagoška statistika [Educational statistics]. Užice, Serbia: Faculty of Education.

Kundačina, M. and Banđur, V. (2007). Akademsko pisanje [Academic writing]. Užice, Serbia: Faculty of Education. 